\title{
Article
}

\section{Of Fire and Smoke Plumes, Polarimetric Characteristics}

\author{
Dusan Zrnic ${ }^{1 *}$, Pengfei Zhang ${ }^{2}$, Valery Melnikov ${ }^{2}$ and Djordje Mirkovic ${ }^{2}$ \\ 1 NOAA/National Severe Storms laboratory; affiliate of the School of Meteorology and El. Engineering \\ University of Oklahoma, Norman OK; dusan.zrnicl@noaa.gov \\ 2 Cooperative Institute for Mesoscale Meteorological Studies; pengfei.zhang@noaa.gov (P.Z.); \\ valery.melnikov@noaa.gov (V.M.); djordje.mirkovic@noaa.gov (D.M.) \\ * Correspondence: dusan.zrnicl@noaa.gov
}

\begin{abstract}
Weather surveillance radars routinely detect smoke of various origin. Of particular significance to the meteorological community are wildfires in forests and/or prairies. For example, one responsibility of the National Weather Service in the USA is to forecast fire outlooks as well as to monitor wild fire evolution. Polarimetric variables have enabled relatively easy recognitions of smoke plumes in data fields of weather radars. Presented here are the fields of these variables from smoke plumes caused by grass fire, brush fire, and forest fire. Histograms of polarimetric data from plumes contrast these three cases. Most of the data are from the polarimetric Weather Surveillance Radar 1988 Doppler (WSR-88D aka Nexrad, $10 \mathrm{~cm}$ wavelength) hence the wavelength does not influence these comparisons. Nevertheless, in one case simultaneous observations of a plume by the operational Terminal Doppler Weather Radar (TDWR, $5 \mathrm{~cm}$ wavelength) and a WSR-88D is used to infer backscattering characteristic and hence sizes of dominant contributors to the returns. In addition, comparisons with observations by other investigators of plumes from urban area but at a $5 \mathrm{~cm}$ wavelength are made. To interpret some measurements Computational Electromagnetics (CEM) tools are applied.
\end{abstract}

Keywords: weather radar; polarimetry; smoke plumes; wild fires; polarimetric characteristics

\section{Introduction}

From 1992 to present, the United States Forest Service has a record of geo-reverenced wildfires in the USA. From their statistics [1], Hoover and Hanson write that since the year 2000 "an average of 72,400 wildfires burned an average of 7.0 million acres per year." This is about the land size of Maryland. The minima of burned land are about 4.0 million acres or 6250 square miles and is close to the land size of Hawaii. The maxima are 10 million acres, which is about twice the land size of Massachusetts. Besides surface damage, the wild fires caused between 12 and 19 firefighters fatalities per year from 2015 to 2018. To reduce the burned acreage and fatalities, early detection of wild fires is imperative. In areas void of population the principal wildfire detecting instruments are satellites and weather radars.

According to the US National Park Service [2] about "85\% of wildland fires in the United States are caused by humans". These include fires started as campfires and left unattended, burning of debris, use of equipment and malfunctions, discarded cigarettes, and arson. Nevertheless, the underlining conditions for recent increase in the occurrence of wild fires is the raising temperature of the atmosphere. 
In this paper, we document polarimetric radar observations of smoke caused by wildfires fueled by different vegetation. Of particular significance to the meteorological community are forests and/or prairies. For example, the US National Weather Service (NWS) issues daily fire weather outlooks. Forecasters at local offices have access to display of weather radar data in which they can identify and track smoke plumes and warn public of this hazard. Related issue is the potential for mudslides and debris flow on steep terrain made barren by wildfires. Predicting these events is at the core mission of the NWS.

Weather surveillance radars routinely detect fires of various origin. Their high sensitivity enables detecting and tracking smoke plumes [3], and support management of wildfires [4]. Detection of wildfires by weather radar is on average $5 \mathrm{~min}$ after ignition compared to the $15 \mathrm{~min}$ delay achieved with good conventional systems [5].

Weather radars also detect smoke from urban area. A good example is the industrial fire in Montreal observed with a $10 \mathrm{~cm}$ wavelength weather radar [6]. The authors document the history of the plume and compare simultaneous observations with a vertically pointing $3 \mathrm{~cm}$ wavelength radar and a $33 \mathrm{~cm}$ wavelength wind profiler. The reflectivities $Z$, measured with the $33 \mathrm{~cm}$ wavelength radar, reach $40 \mathrm{dBZ}$ while those measured at the $3 \mathrm{~cm}$ wavelength are about $20 \mathrm{~dB}$ lower. One explanation is that the particles' sizes approximately $1 \mathrm{~cm}$ caused Mie scattering at the $3 \mathrm{~cm}$ wavelength while at the $33 \mathrm{~cm}$ wavelength the scattering was in the Rayleigh regime characterized with significantly larger cross section and consequently stronger reflectivity $Z$. In addition, the authors [6] hypothesize that refractive index irregularities also contributed to the difference. However, others [7] suggest that coherent scattering from the particles in smoke may be significant and would explain the correlation between the reflectivities at the two wavelengths.

In [8] researchers document the polarimetric characteristics of a grass fire whereas in [9] the authors write about dual polarization characteristics, at $5 \mathrm{~cm}$ wavelength, of an apartment fire. They found mean reflectivity of $9 \mathrm{dBZ}$ within the plume and maximum values of $20 \mathrm{dBZ}$. Their mean differential reflectivity, $Z \mathrm{DR}$ is $1.7 \mathrm{~dB}$, similar to values in rain but the low correlation coefficient (less than 0.5 ) clearly indicates nonmeteorological scatterers.

We present polarimetric characteristics of smoke from a grass fire in Oklahoma, forest fire in New Mexico, and brush fire near Loss Angeles, California. We use data from WSR-88Ds, which have wavelength of $10 \mathrm{~cm}$. For comparison and estimation of dominant scatterers, we compare the reflectivities from the Oklahoma WSR-88D with those measured on the TDWR, which surveys the Oklahoma City airport. That radar's wavelength is $5 \mathrm{~cm}$.

\section{Examples of Observed Smoke Plumes}

This section describes observations of smoke plumes from three wildfires.

\subsection{Grassfire in Oklahoma}

In 2017, Oklahoma experienced a dry spell, which contributed to several wildfires. One started late in the morning on Feb 12, 2017, 10 to $20 \mathrm{~km}$ southwest from the Oklahoma City Operational WSR88D (Fig. 1). The radar has dual polarization, wavelength $\lambda=10 \mathrm{~cm}$, beamwidth $1^{\circ}$, sample spacing 


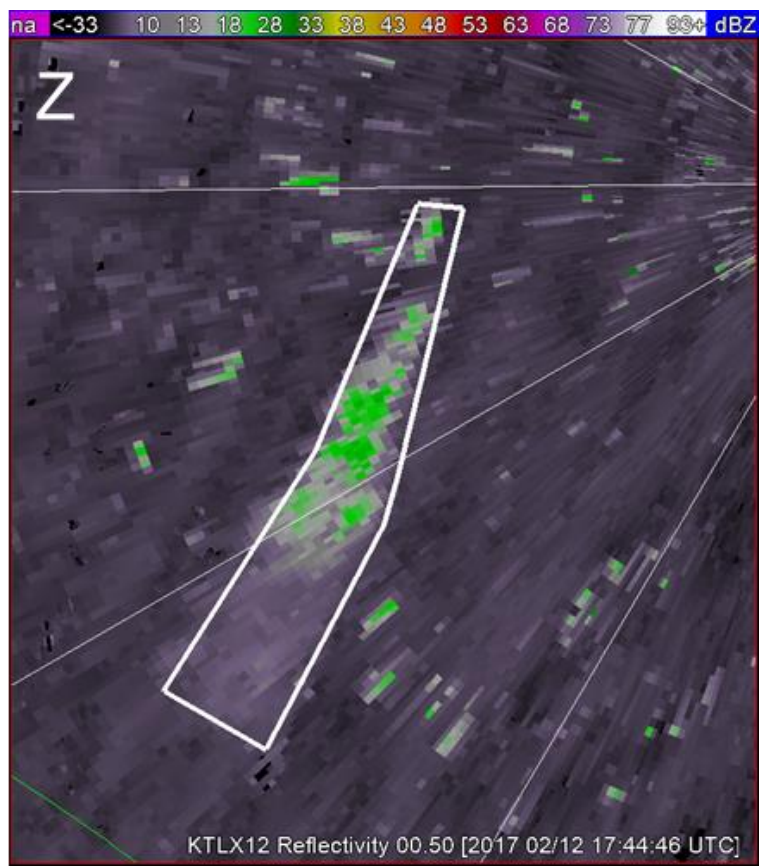

(a)

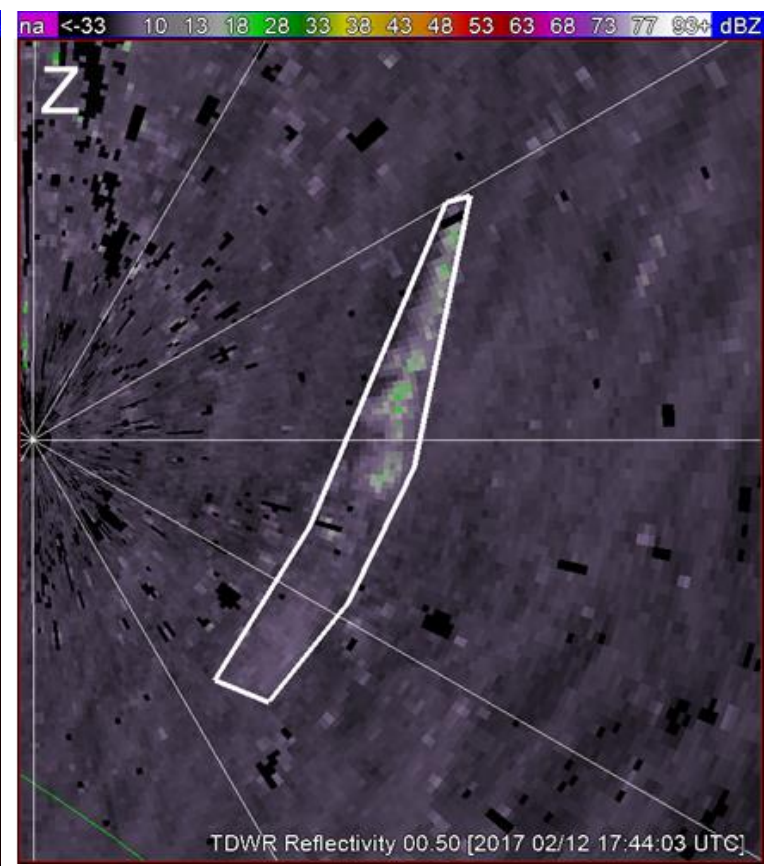

(b)

Figure 1. Observed reflectivity fields: (a), with the Oklahoma City WSR-88D $(\lambda=10 \mathrm{~cm}$, code name KTLX), and (b), TDWR ( $\lambda=5.35 \mathrm{~cm}$, code name TOKC) located in Norman for surveillance of the Will Rogers Airport. The color bar indicates reflectivity in dBZ. Date is 2/12/2017 and the polygons encompass the plumes.

$250 \mathrm{~m}$, and range resolution $235 \mathrm{~m}$. The fire was also observed with the $5 \mathrm{~cm}$ wavelength, TDWR, which monitors weather hazards over the Oklahoma City Will Rogers Airport. The radar has linear horizontal polarization, beamwidth $0.5^{\circ}$ and sample spacing and range resolution of $150 \mathrm{~m}$. Obvious in these figures are larger reflectivity estimates at the 10 -cm wavelength (WSR-88D) compared to the ones at the 5-cm wavelength (TDWR). The histograms of the reflectivities (Fig. 2a) quantify this

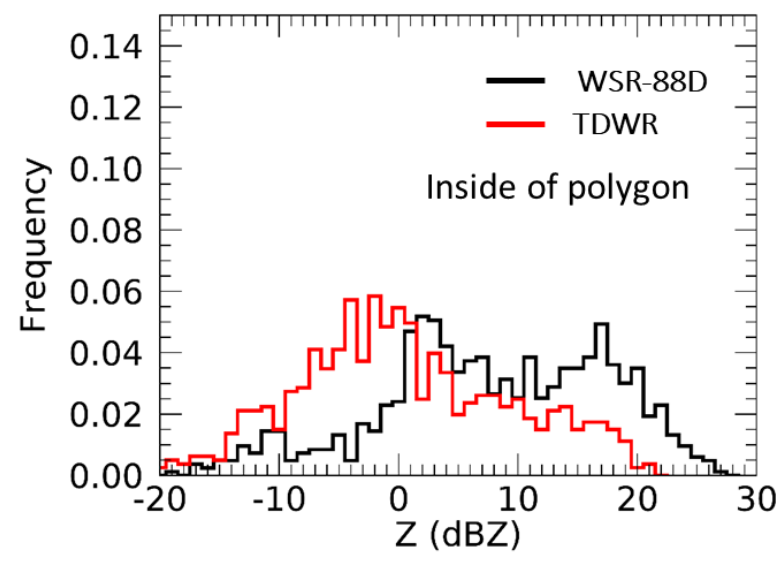

(a)

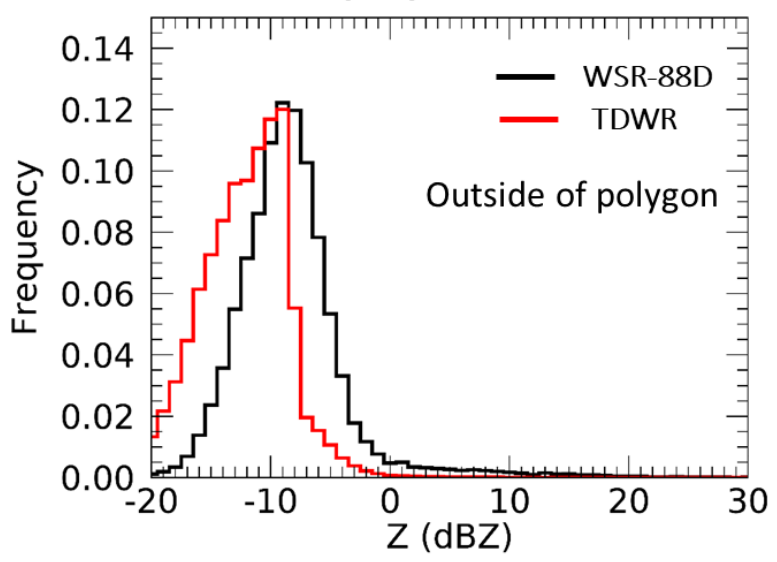

(b)

Figure 2. Histograms of reflectivity (a) within the enclosed areas in Fig. 1; black is from the WSR-88D and red is from the TDWR. (b) Same as in (a) except the histograms are from the areas out of the enclosure. The tail of the distribution from the WSR-88D extends to $30 \mathrm{dBZ}$ whereas the one from the TDWR extends to $20 \mathrm{dBZ}$. 
difference and the reason is in the type of scattering, which we discuss shortly. This is in contrast to the regions outside of the polygons from which the histograms are very similar (Fig. 2 b). The offset of about few $\mathrm{dB}$ might be due to Bragg scattering by refractivity irregularities. The reflectivity $\mathrm{Z}$ is proportional to the structure parameter $C_{n}^{2}$ of the refractive index fluctuations [10]:

$$
\log \left(C_{n}^{2}\right)=-11.5+0.1 Z
$$

where $Z$ is in $d B Z$. These fluctuations are very often present in the boundary layer and can produce reflectivities up to $-3 \mathrm{dBZ}$ [11] at the $10 \mathrm{~cm}$ wavelength. At the $5 \mathrm{~cm}$ wavelength the sizes of the potentially contributing eddies is $2.5 \mathrm{~cm}$ and these are more likely to be in the dissipative range of turbulence than the $5 \mathrm{~cm}$ sizes that contribute coherently to the reflectivity at the $10 \mathrm{~cm}$ wavelength. Note that most of the Zs in the histogram (Fig. 2b) from WSR-88D (10 cm wavelength) are smaller than $-3 \mathrm{dBZ}$ and overlap the Bragg scattering values in [11]

As an aside, there are some speckles of $Z$ close to $30 \mathrm{dBZ}$ in the data from WSR-88D (Fig. 1 a) and none in the data from TDWR (Fig. 1b). We speculate that the sporadic spackles are from scatterers that are in the Mie regime at the shorter wavelength but still in the Rayleigh regime at the $10 \mathrm{~cm}$ wavelength. They could be birds. Their number is very small and appears in the tail of the distribution (Fig. 2b).

We hypothesize that the difference in reflectivities (Fig. 2a) off the plume is caused by ash debris that is in the Mie regime of scattering at the $5 \mathrm{~cm}$ wavelength but still in the Rayleigh at the $10 \mathrm{~cm}$ wavelength. During burning of vegetation the oils burn fist and the water evaporates leaving carbon and minerals. Some carbon may burn into carbon dioxide or monoxide. Often the carbon burning is incomplete leaving solid residue. In such cases, the biomass (leaves, grass) retains the original shape.

To test quantitatively this hypothesis we took few pieces of dry leaves and let them fall. By observing their orientation, we identified three main modes. In one, the leaf piece sways back and forth like a pendulum while continuously changing the direction of the sway. In another mode, it rotates about the vertical axis (like a helicopter propeller but going down). The third pronounced mode is tumbling, which often changes to swaying.

We approximated the leaf with a pentagon (inset in Fig. 3) and computed its reflectivity using the WIPLE-D software $[12,13]$. We set the relative permittivity to $7+j 2$, a value of carbon black [14] and the thickness of the plate to $0.1 \mathrm{~mm}$, typical of leafs. We specified random orientation of the plate in terms of its yaw $\left(360^{\circ}\right)$, pitch $\left( \pm 30^{\circ}\right)$ and $60^{\circ}$ of roll when the roll axis is in the horizontal plane. We set up the numerical computation to automatically generate the $Z_{\mathrm{e}}$ in $\mathrm{mm}^{6} \mathrm{~m}^{-3}$. Then we computed the average reflectivities at horizontal polarization. For illustrative purpose, we compared the $Z_{\mathrm{e}}$ with the values in the histogram and applied a concentration that matches the reflectivity ( $10 \mathrm{~cm}$ wavelength) of $25 \mathrm{dBZ}$. To do so required subtraction of $15 \mathrm{dBZ}$ from the curves valid at concentrations of $1 \mathrm{~m}^{-3}$. This means that the plates' concentration equals $10^{-1.5} \mathrm{~m}^{-3}$. The span of plates' reflectivities for which $\mathrm{Ze}(\lambda=10 \mathrm{~cm})>\mathrm{Ze}_{\mathrm{e}}(\lambda=5 \mathrm{~cm})$ is from sizes 10 to over $50 \mathrm{~mm}$ (Fig. 3). 


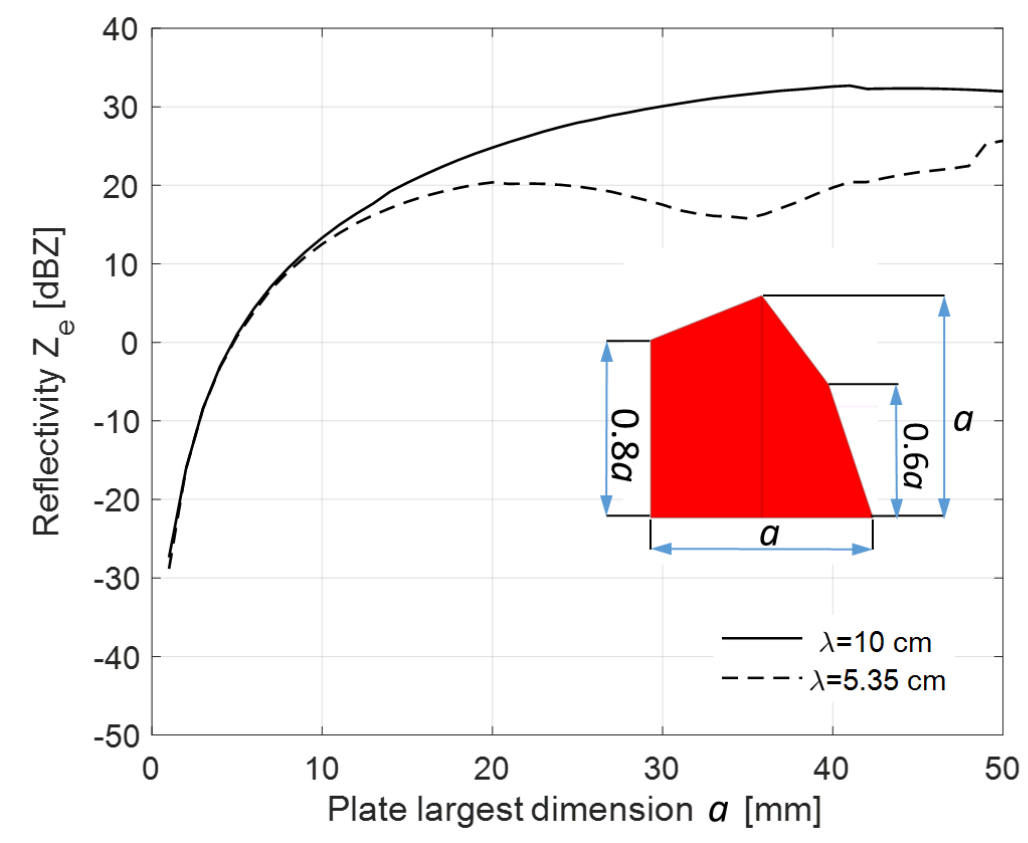

Figure 3. Reflectivity of a pentagonal plate (inset) representing ashes from vegetation with the thickness of $0.1 \mathrm{~mm}$ and permittivity $7+\mathrm{j} 2$. The concentration is $10^{-1.5} \mathrm{~m}^{-3}$, and the dimension $a=$ $1.02 D$, where $D$ is a diameter of a circle with the same area as the plate.

The distance from the WSR-88D to the plume's centroid is $15 \mathrm{~km}$ and from the TDWR it is 10 $\mathrm{km}$. At these distances and using information in Fig. 2a and Fig. 3, we illustrate a possible number of scatterers in the WSR-88D and TDWR resolution volumes. The beamwidths of the WSR-88D and TDWR are $0.95^{\circ}$ and $0.5^{\circ}$ and the widths of the range weighting functions are $235 \mathrm{~m}$ and $150 \mathrm{~m}$. These specify the resolution volume sizes (i.e., volume within which the radar weighting function is equal or larger than $1 / 4$, i.e., $-6 \mathrm{~dB}$ of its maximum [10]. The corresponding volume sizes are $11.42 \cdot 10^{6} \mathrm{~m}^{3}$ for the WSR-88D and $0.9 \cdot 10^{6} \mathrm{~m}^{3}$ for the TDWR. Assume the scatterer sizes are $20 \mathrm{~mm}$, so that $\mathrm{Z}_{\mathrm{e}}=25 \mathrm{dBZ}$ for the WSR-88D and $20 \mathrm{dBZ}$ for the TDWR. If so, there would be about 361000 scatterers in the resolution volume of the WSR-88D, and 28300 scatterers in the TDWR's resolution volume. In actuality, the scatterers have a distribution of sizes and do not fill the resolution volumes. Although this challenges quantitative interpretation, the basic conclusion that Mie scattering causes the difference in Zes stands.

Fig. 4 displays the fields of radar variables obtained from this fire with the WSR-88D. Background patterns indicate convective rolls, which form when low-level air in the planetary boundary layer is unstable but capped by a stable layer. The polarimetric variables are typical of 

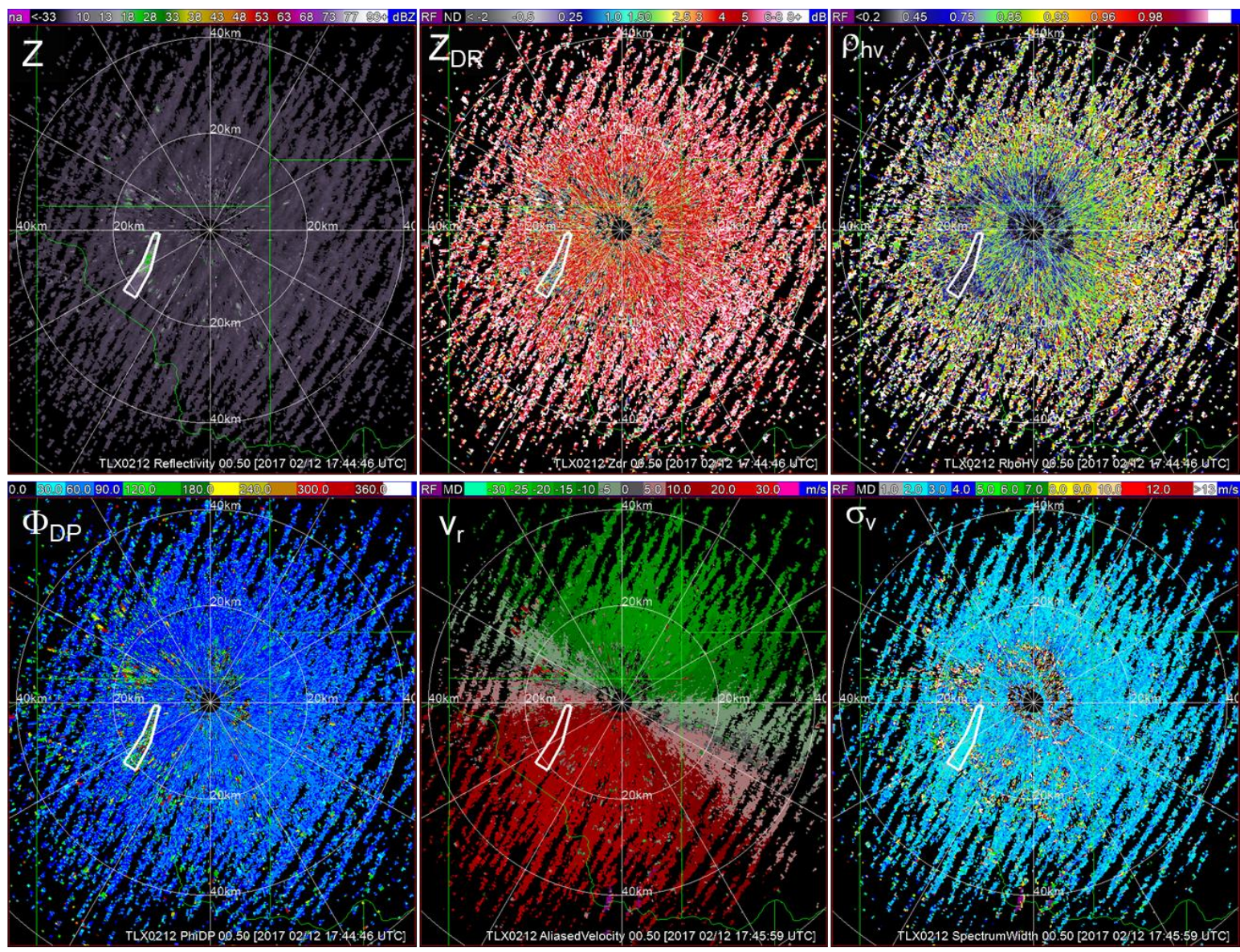

Figure 4. Fields of reflectivity, differential reflectivity, correlation coefficient, differential phase, Doppler velocity, and spectrum width. The radar is WSR-88D (Oklahoma City, code designation KTLX), elevation angle is $0.5^{\circ}$, and the date is Feb/12/2017. The color bars indicate dBZ units for reflectivity $Z, d B$ for differential reflectivity $Z \mathrm{DR}$, degrees for differential phase $\Phi_{\mathrm{DP}}$, and $\mathrm{m} \mathrm{s}^{-1}$ for Doppler velocity $v_{\mathrm{r}}$ and spectrum width $\sigma_{\mathrm{v}}$. Data from the smoke plume are inside the polygons.

insects. Notable in the plume are positive differential reflectivities ( $Z_{\mathrm{DR}}$ ) of about $2 \mathrm{~dB}$, low correlation coefficients ( $\rho_{\mathrm{hv}}$ ) of about 0.6 , large differential phases $\left(\Phi_{\mathrm{DP}}\right)$, smooth Doppler velocity field of about $20 \mathrm{~m} \mathrm{~s}^{-1}$, and consistent spectrum widths $\left(\sigma_{\mathrm{v}}\right)$ of about $2 \mathrm{~m} \mathrm{~s}^{-1}$. The system differential phase on the WSR-88D, $\Phi_{\mathrm{DP} \text { sys }}$ is $60^{\circ}$ hence the backscatter differential phase $\left(\delta=\Phi_{\mathrm{DP}}-60^{\circ}\right)$ spans a very large range (Fig. 5) exceeding that of birds, which can be $0^{\circ}$ to $120^{\circ}$ [15]. The Doppler velocity field shows northeast wind at about $10 \mathrm{~m} \mathrm{~s}^{-1}$ and confirms that the smoke particles are very good wind tracers. The spectrum widths in the plume are on the average $1 \mathrm{~m} \mathrm{~s}^{-1}$, and in the environment, these are $2 \mathrm{~m}$ $\mathrm{s}^{-1}$ (Fig. 5). The difference we attribute to the geometry: the plume is aligned with the roll and the beam is almost parallel to the roll's axis. Therefore, the rotation components of rolls are nearly perpendicular to the beam axis and contribute minimally to the spread of Doppler velocities within the resolution volume. The histogram of $\sigma_{\mathrm{v}}$ from the environment is a bit larger. Data from all azimuths are included in the histogram making it wider and increasing its mean value.

Histograms of the polarimetric variables from the plume (Fig. 5) depict the $Z_{\mathrm{DR}}$ range from $-4 \mathrm{~dB}$ to over $8 \mathrm{~dB}$, which is the maximum recordable on the WSR-88Ds. We see a large spread of backscatter differential phase with positive values prevailing. The standard deviation of $\Phi_{\mathrm{DP}}$ is about 

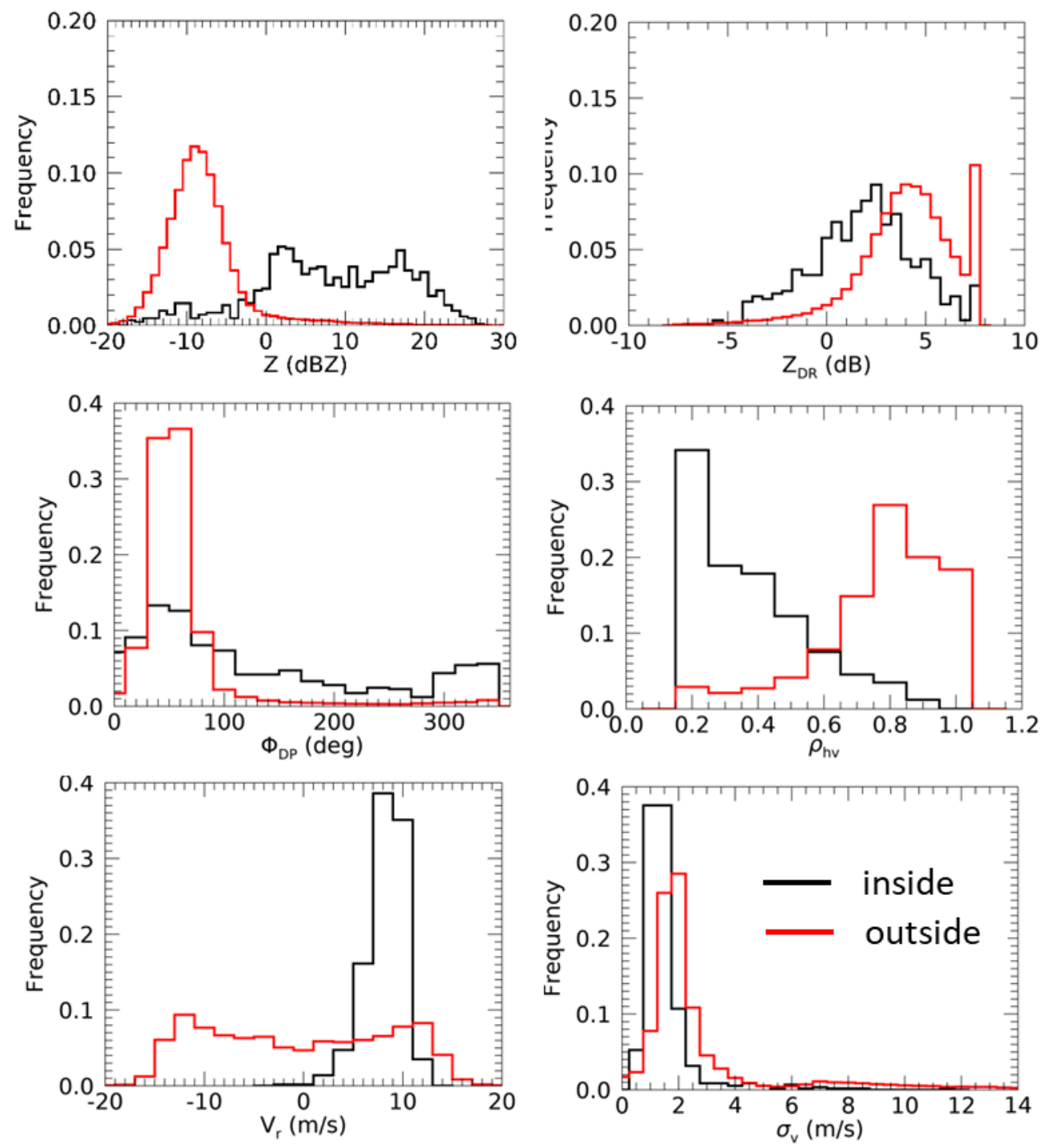

Figure 5. Histograms of the polarimetric variables, from the smoke plume (black) and from the area outside of the plume (red).

$2.5^{\circ}$, formula for computing it is in [16], so the values at high $\Phi_{\mathrm{DP}}$ are unlikely due to uncertainty of estimates. The probable cause is couplings of the $\mathrm{H}$ and $\mathrm{V}$ components via canted smoke particles upon backscattering [17]. The simultaneous mode (SHV) of polarimetric measurements is prone to coupling, and the "inferred" (wrong) differential phase depends on the differential phase upon transmission, on orientation of the scatterer, on relative reflections at the two polarization, and on the backscatter differential phase. These factors create a wide spread of $\delta$. The histograms of the same variables (Fig. 5) overlap. The best separation between values from fireworks and environment is in the histograms of the reflectivity and correlation coefficient, but some separation is evident in the other two polarimetric variables, as well. Based on the histograms it is possible to construct fuzzy logic membership functions and/or priory probabilities for Bayesian classifiers.

The plume extent in height is about $1.1 \mathrm{~km}$, which is the top of the boundary layer as can be best seen in the fields of $\rho_{\mathrm{hv}}$ (Fig. 6). 


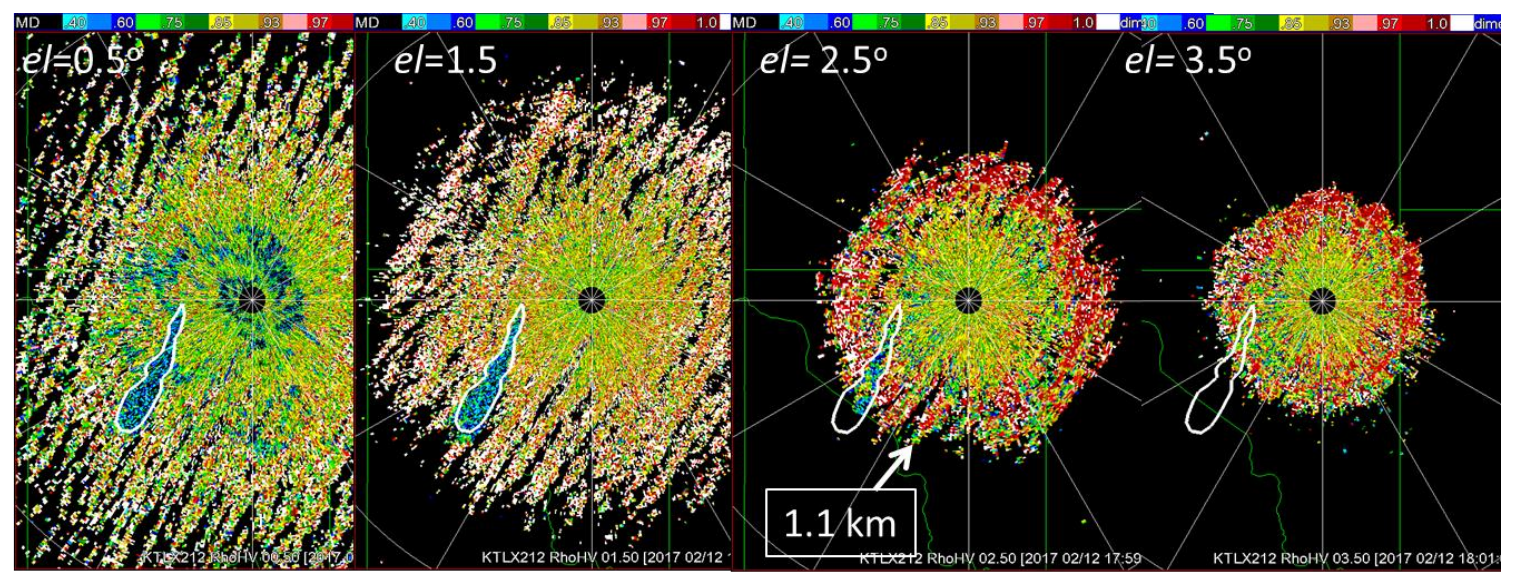

Figure 6. Fields of correlation coefficient $\rho_{\mathrm{hv}}$ at consecutive scans in elevations as indicated.

\subsection{Little Bear wildfire in New Mexico}

On June 4, 2012, lightning ignited a fire in the Little Bear area of the Lincoln National Forest northwest from Ruidoso, NM. By June 8, preliminary defense line was completed around the fire

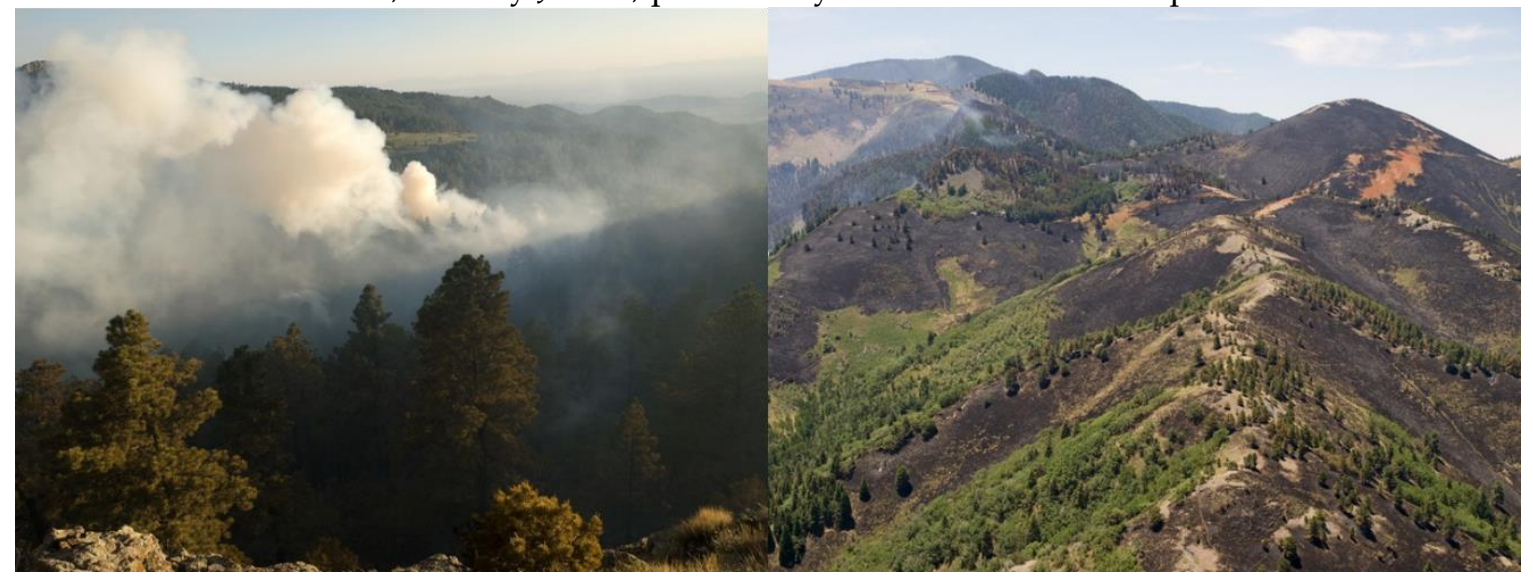

Figure 7. (left) Photograph of Little Bear fire on June 92012 (courtesy of Kari Greer, USFS). (right) Photograph of the burned area.

perimeter, but on June 8 strong winds blew fire embers beyond the perimeter. The fire burned more than 44000 acres, 242 houses, and 12 structures. The photograph in Fig.7 (left) depicts the fire on June $8^{\text {th }}$ and the burnout terrain is in Fig. 7 (right). The artificial color image (Fig. 8) shows a broad 
view of the area.

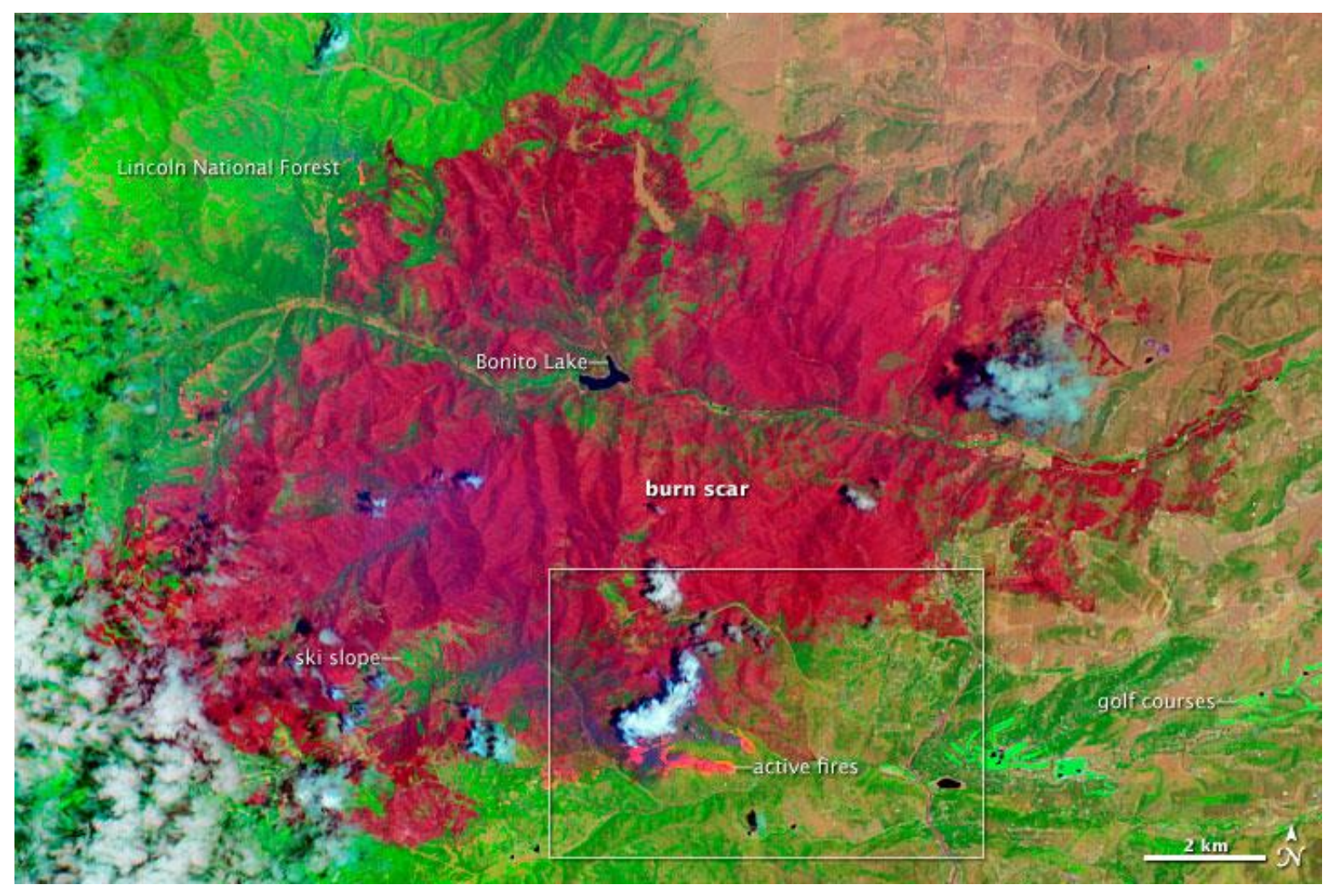

Figure 8. False color image of the fire taken by the advanced Land imager on NASA's Earth Observing - 1 (EO-1) satellite. Shades of red indicate the burn scars, active fire is in orange-red colors, and sparsely vegetated area is in green-yellow color.

Figs. 9, 10, and 11 depict fire progression over one-hour time as registered by radar and camera on a satellite. The WSR-88D is at Holloman NM and its code designation is KHDX. Noteworthy are the relatively high values $(\sim 30 \mathrm{dBZ})$ of the reflectivities. The largest Zs are at the SW part above the location of intense burning. The fire generated updraft lofts debris, which is highly concentrated in the updraft and likely, contains largest scatterers (possibly carbonated grass, or leaves etc.). The relatively low $Z_{\mathrm{DR}}$ (about $1 \mathrm{~dB}$ ) depicts well the updraft location. The particles on the average tend to be horizontally oriented, are likely wobbling due to turbulence and sheer in the updraft, lowering the effective ZDr. Farther downwind (to the NE) there is a secondary maximum of $Z$ coincident with a very large differential reflectivity. We do not know the exact composition of scatterers but from the low $\rho_{\text {hv }}$ we suspect that it consists of debris in the plume. It has settled into predominantly horizontal orientation and exhibits significant wobbling. It is also possible that smoke aerosols act as condensation nuclei causing crystal formation (needles and plates) and growth, which further add to the reflectivity and differential reflectivity. In either case, the low values of the correlation coefficient (0.6) suggest that there is significant flutter (random canting) of the particles. 


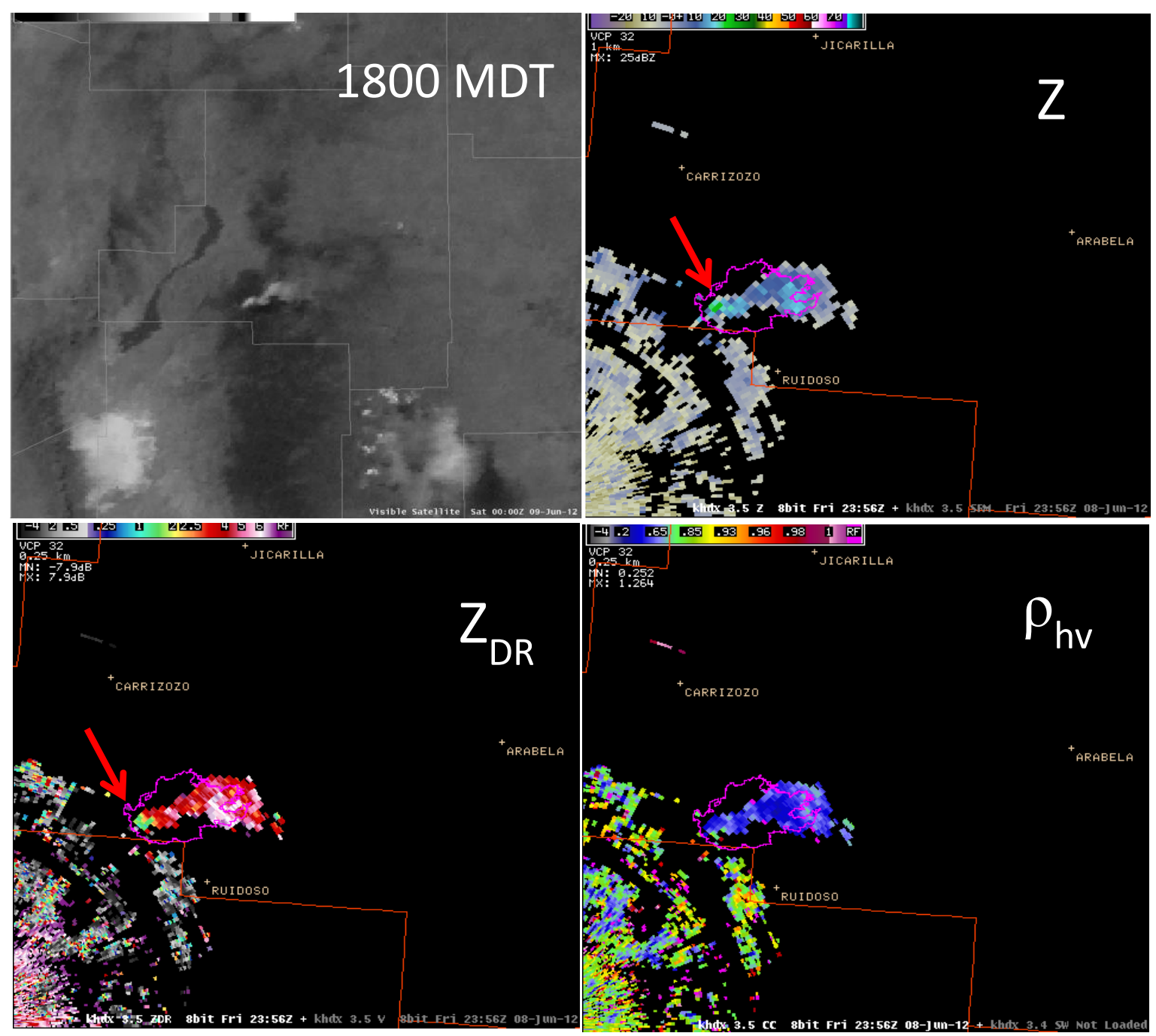

Figure 9. Little Bear fire on June 8 at 1800 MDT indicated on the NASA satellite photo (upper left). Field of reflectivity Z from the WSR-88D (Holloman Air Force Base NM, code designation KHDX) at the same time. Field of differential reflectivity, ZDR. Field of the correlation coefficient, $\rho_{\mathrm{hv}}$. The elevation angle is $3.5^{\circ}$ and time is $23: 56 \mathrm{UT}$, and the fields were generated by the NWS).

Refractivity variations caused by the fire could also contribute to the reflectivity [6] and influence the other polarimetric variables. From eq.1 it follows that the structure parameter of refractivity variations $C_{n}^{2}$ should be $10^{-9} \mathrm{~m}^{-2 / 3}$ to create a $25 \mathrm{dBZ}$ return. This is two orders of magnitude larger than the value cited as "very intense" maxima observed in the boundary layer [18]. It is unknown if fires can create such large values. Fires might create much smaller values comparable to natural fluctuation, which are likely present and overwhelmed by smoke debris. 


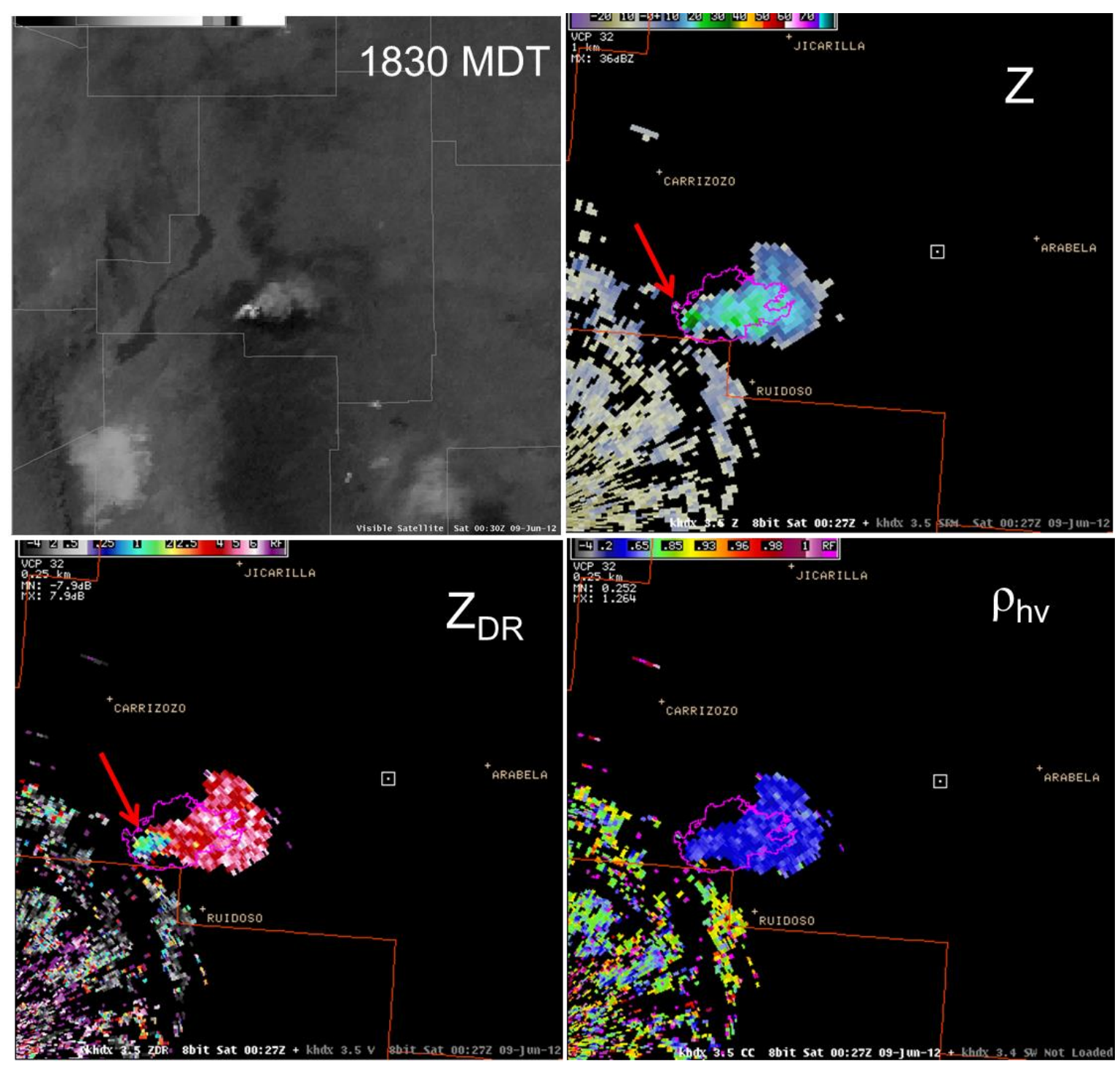

Figure 10. Same as in Fig. 9 except 30 minutes later (radar time is 00:27 UTC). 


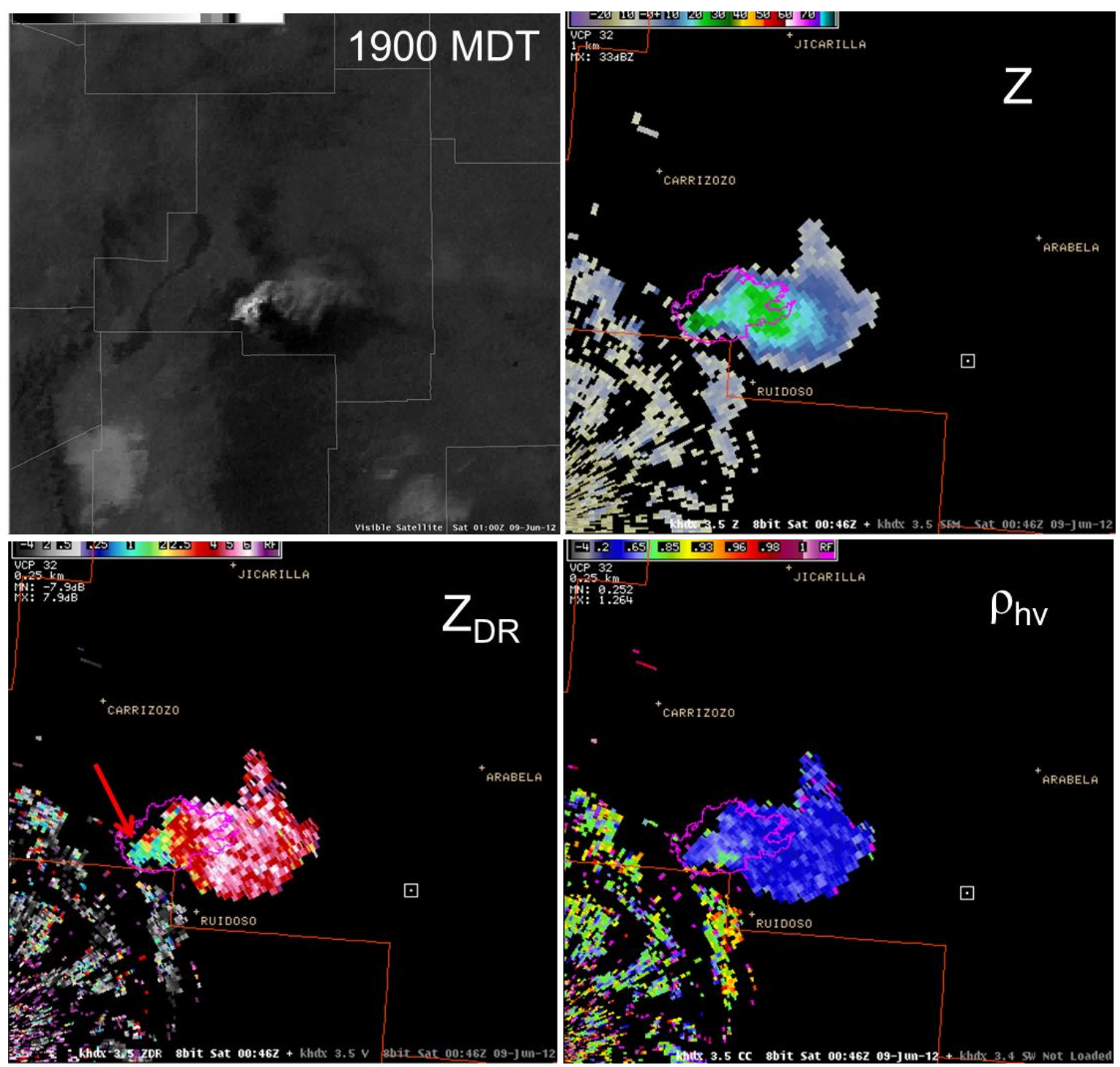

Figure 11. Same as in Fig. 9 but one hour later (radar time is 00:46 UTC).

In Fig. 12 are plots of the vertical profiles of the polarimetric variables. These we constructed from the conical scans and the line in Fig. $12 \mathrm{~b}$ depicts the location of the vertical slice. The returns extend over $6 \mathrm{~km}$ above sea level but the actual top is missing because it exceeds the height at the maximum available elevation of $4.5^{\circ}$. The blob of $Z$ indicates that the particles are suspended aloft and above the boundary layer. The differential phase values are between the systems phase (about $60^{\circ}$ ) and about $100^{\circ}$ implying that the backscatter differential phase is between $0^{\circ}$ and $40^{\circ}$. This means that some scatterers are in the Rayleigh regime while other may be oriented and inducing coupling. The differential reflectivities exhibit values in excess of $8 \mathrm{~dB}$. The correlation values are between 0.6 and 0.7 indicating preponderance of nonmeteorological scatterers. The spectrum widths away from the source of smoke (i.e., fire) are smaller than $4 \mathrm{~m} \mathrm{~s}^{-1}$ and closer to the updraft the values are $8 \mathrm{~m} \mathrm{~s}^{-1}$. Turbulence at the transition from the updraft and the environmental flow has likely caused these spectrum widths. At the location of largest spectrum width there is a local $25 \mathrm{~m} \mathrm{~s}^{-1}$ maximum of Doppler velocity away from the radar (not shown). This may be the beginning of the divergent flow at the top of the plume. It is interacting with the environmental wind and creating turbulence. 

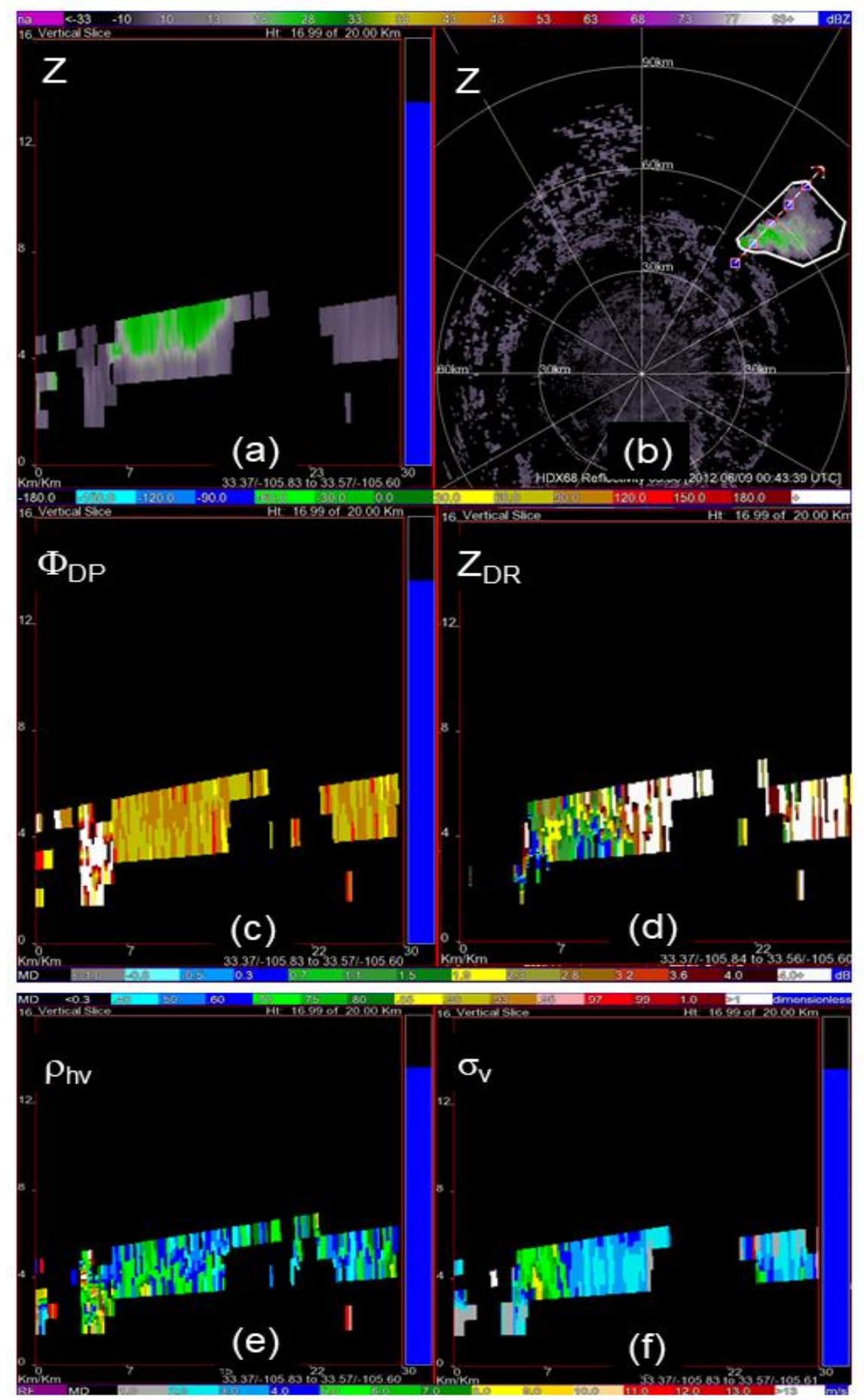

Figure 12. (a) Vertical cross section of $Z$ through the plume. (b) Field of $Z$ plotted as PPI at the elevation of $3.5^{\circ}$, the arrow indicates location of the vertical cross sections. (c) Same as in (a) except the differential phase is shown. (d) Same as in (a) but the cross section is of differential reflectivity. (e) RHI of the correlation coefficient. (f) Same as in (a) but the plot shows the spectrum width. The top color bar indicates values of reflectivity (dBZ), the second from top color bar indicates the values of differential phase (deg), the third color bar depicts values of $Z_{D R}(d B)$, and the bottom (forth) color bar depicts values of the spectrum width. The ground altitude at the fire location is $2.9 \mathrm{~km}$ above mean sea level. Radar time is 00:43 UTC and the range rings are at 30, 60 and $90 \mathrm{~km}$. 
To determine the top of the plume we took data from the WSR-88D at Albuquerque NM, which is about $210 \mathrm{~km}$ away from the plume (Fig. 13). The plume appears only at the $0.5^{\circ}$ and $1.5^{\circ}$ elevation scans and the maximum of reflectivities are $22 \mathrm{dBZ}$ and $16 \mathrm{dBZ}$. Note that the $Z_{\max }$ in Fig.12a is about $30 \mathrm{dBZ}$, clearly larger because at the close range of the Holloman radar smoke particles fill its beam. The beam center of the Albuquerque radar at the $1.5^{\circ}$ elevation is $10.2 \mathrm{~km}$ above sea level and the lateral beam width is about $3.75 \mathrm{~km}$. If the plume fills the lower part of the beam, it follows that its height would be about $8 \mathrm{~km}$. The liquid condensation level on that day was $5.3 \mathrm{~km}$. Therefore, the updraft likely created a cloud in which ice crystals coexist with smoke.

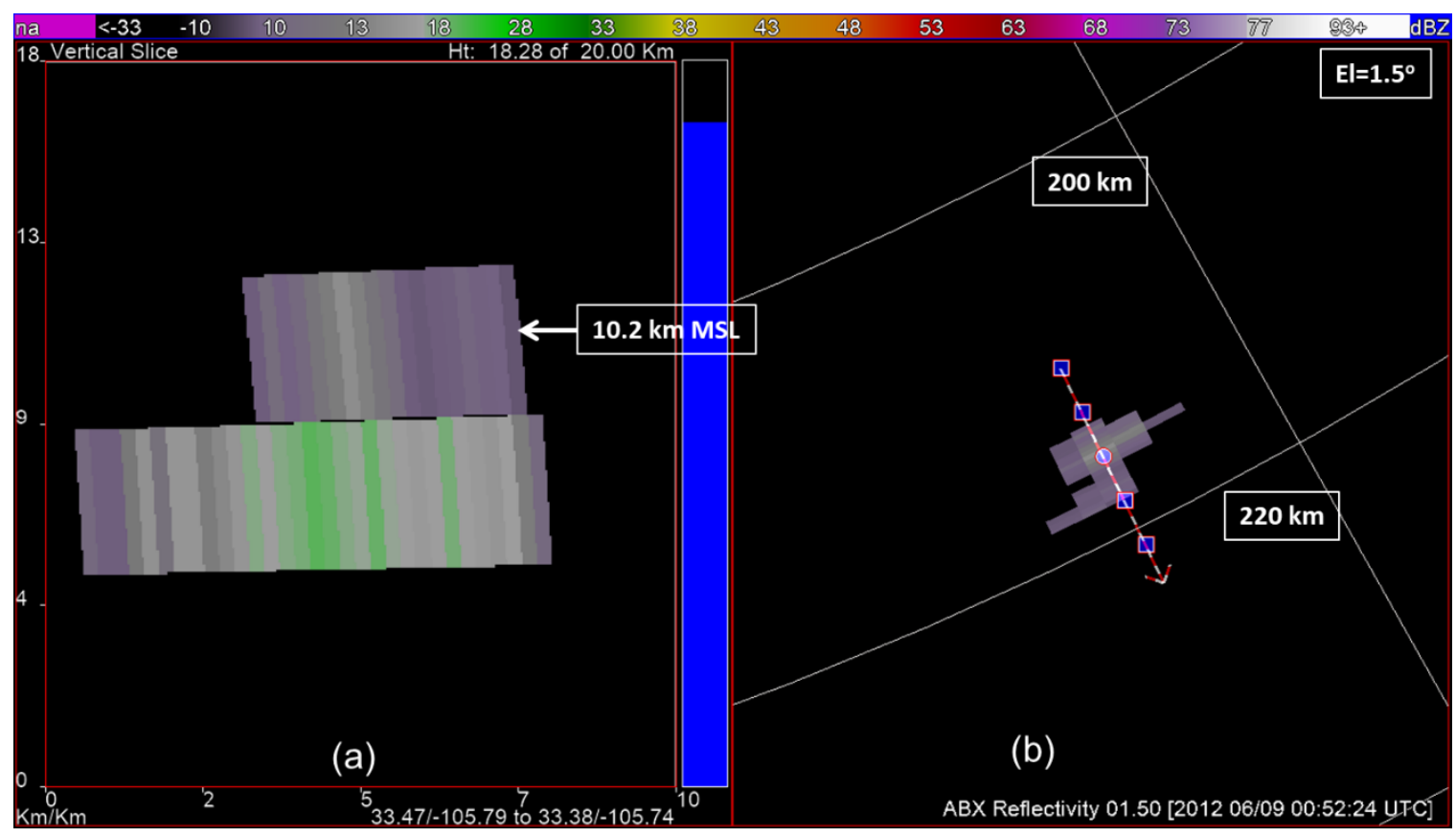

Figure 13. (a) Vertical cross section of reflectivity obtained with the Albuquerque WSR-88D (in NM, code designation $\mathrm{KABX}$ ). (b) Reflectivity field at the $1.5^{\circ}$ elevation scan. The line with the arrow indicates the radial along which the vertical cross-section in (a) is plotted. The color bar indicates the reflectivity values (dBZ) and the time is 00:52 UTC. The range marks encompass the smoke.

Scattergrams of $Z, Z_{\mathrm{DR}}$ and $Z, \rho_{\mathrm{hv}}$ (Fig. 14) are contained within approximately rectangular domains suggesting that these variables are independent. Hence, for fuzzy logic type classification the one dimensional membership functions (at least for these variables) would suffice. For example, the membership function for $Z$ would have values of 1 between 0 and $25 \mathrm{dBZ}$ and could taper (decrease) linearly to 0 at higher and lower $Z$ values. The membership function for ZDR could be one between 0 and $8 \mathrm{~dB}$, however we alert the reader that the value of $8 \mathrm{~dB}$ is the maximum that is currently possible to record on the WSR-88D. (Plans are to extend the maximum values.) The membership function for the correlation coefficient could have a value of one between about 0.2 and 0.8. It appears that the minimum is 0.2 . 

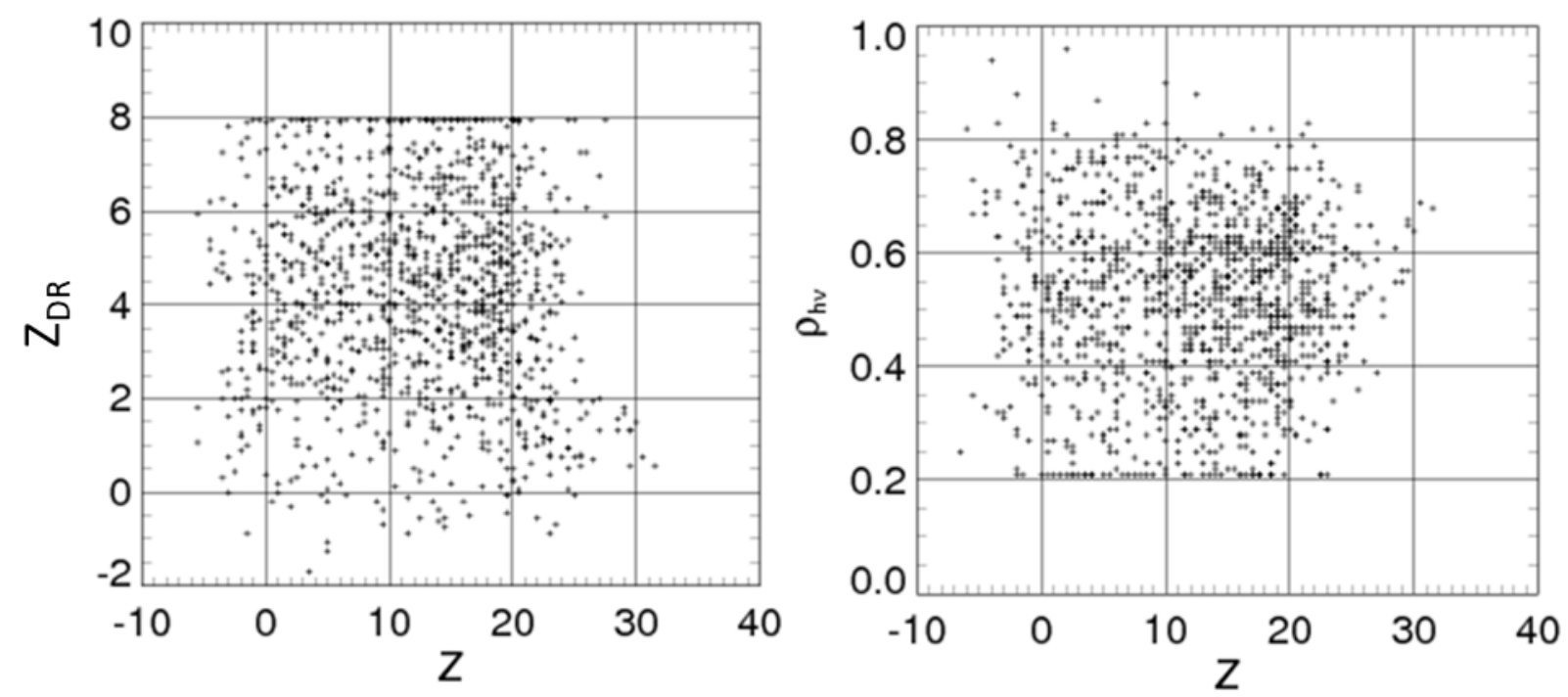

Figure 14. Scattergrams: (left) of $Z_{\mathrm{DR}}, Z$, and (right) $\rho_{\mathrm{hv}}, Z$ from the smoke plume in New Mexico.

Histograms of the data from the fire's patch (manually identified), indicate the mean values and spread (Fig. 15). The mean values are about $12.5 \mathrm{dBZ}$ reflectivity, $4.5 \mathrm{~dB}$ differential reflectivity, and 0.5 correlation coefficient. We have plotted also the total differential phase and its mean value of about $60^{\circ}$ represents the system differential phase; that is, the differential phase encountered in the transmission chain and reception chain. The spread about the mean is mostly from statistical fluctuations as the standard deviation is approximately $2.5^{\circ}$. The radial velocity $v_{r}$ of about $6 \mathrm{~m} \mathrm{~s}^{-1}$ represents the advection component, and the spectrum width $\sigma_{\mathrm{v}}$ up to $3 \mathrm{~m} \mathrm{~s}^{-1}$ suggests presence of some turbulence. 

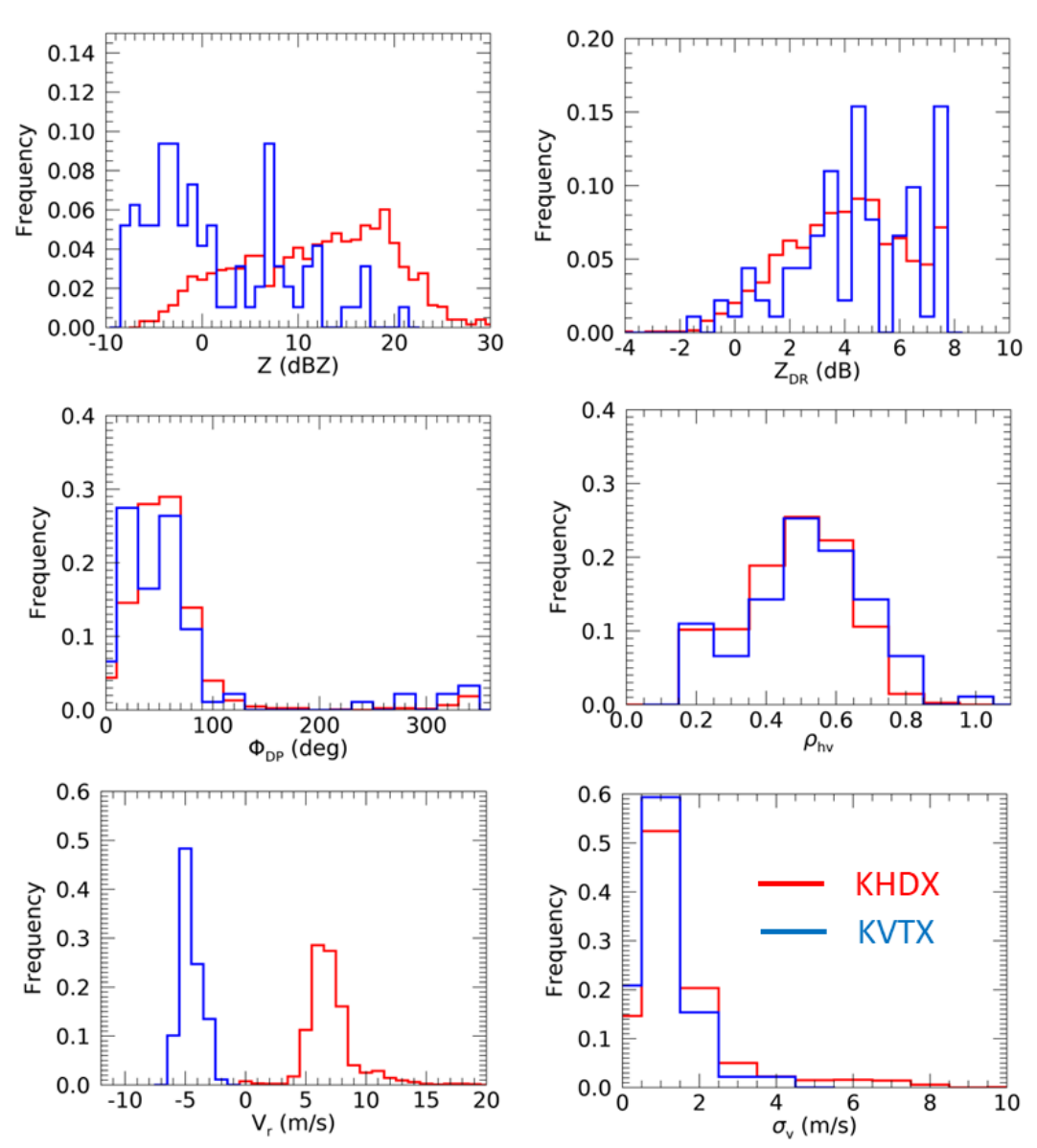

Figure 15. Histograms of the polarimetric variables. The red graphs stand for the New Mexico smoke plume (KHDX WSR-88D, el = 3.5 $5^{\circ}$ and time is 00:43 UTC). The blue graphs are from the Los Angeles brush fire obtained with the WSR-88D, code name KVTX, el =2.5 (time is 21:58 UTC). Date is June 17, 2017. Range rings indicate 30 and $60 \mathrm{~km}$

\subsection{Brushfire near Castaic Lake, California}

This fire started at 13:55 PDT, on June 17, 2017. The fire burned about 800 acres of brush before it was contained a week later. The fields of polarimetric variables and Doppler velocities from smoke plume have values similar to the ones corresponding to the background consisting of biological scatterers (Fig.16). The principal distinction is that the smoke is isolated outside the range where biological scatterers are present. It is likely the biological scatterers (insects) are close to the ground and therefore the beam at range larger than about $40 \mathrm{~km}$ overshoots them. 

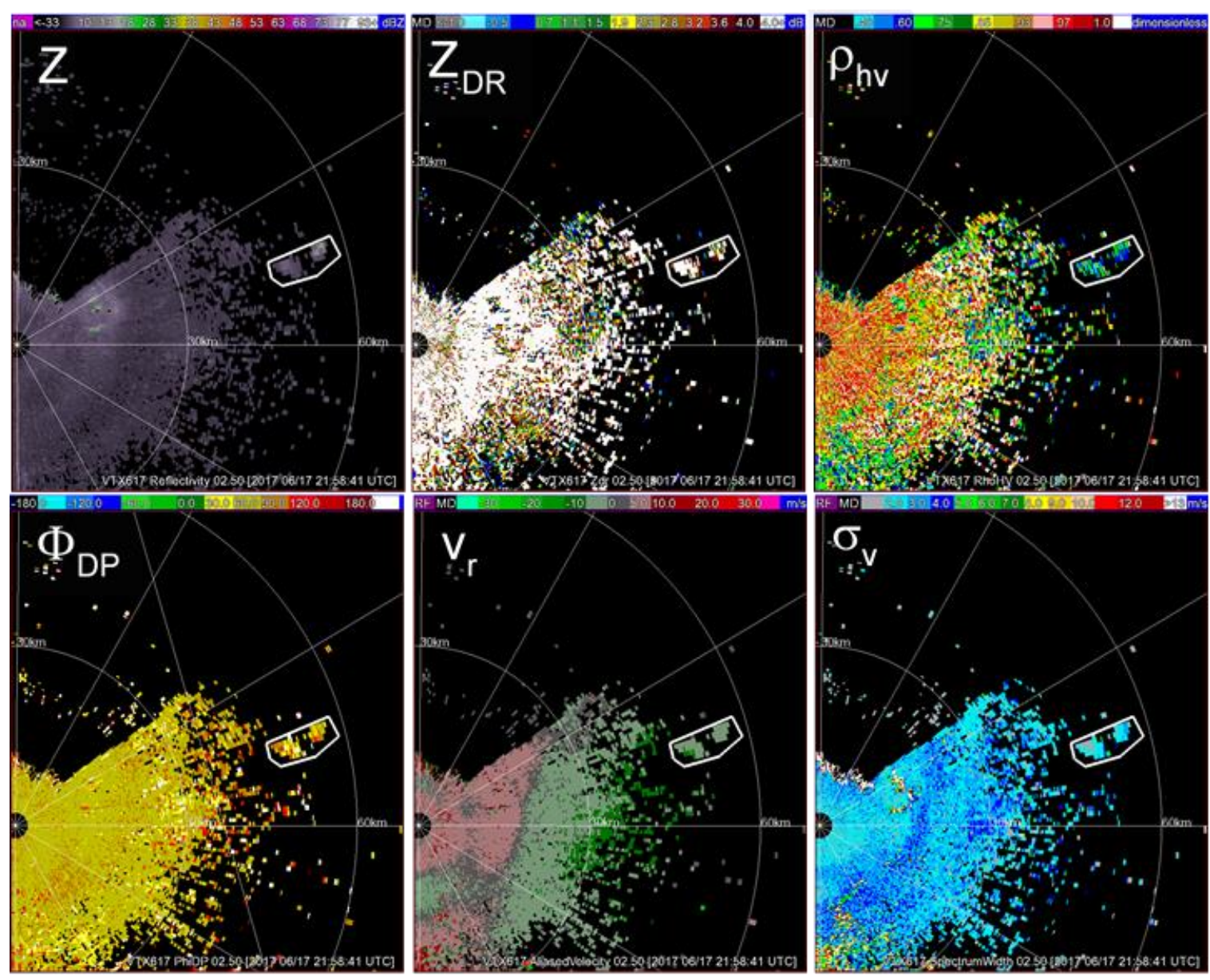

Figure 16. The fields of the polarimetric variables at the time of the brush fire near Castaic Lake CA on June 17, 2017. The radar is a WSR-88D in Los Angeles (code designation KVTX). The polygon encircles the smoke plume, the elevation angle is $2.5^{\circ}$, the time is $21: 58 \mathrm{UTC}$, and the range marks are at 30 and $60 \mathrm{~km}$.

Histograms of the polarimetric variables from the two plumes are in Fig. 15. With the exception of reflectivity, the histograms of the polarimetric variables from the two events are very similar. Most Doppler spectrum widths are contained in the 0 to $2 \mathrm{~m} \mathrm{~s}^{-1}$ interval suggesting weak turbulence. The mean differential phase equals the system phase indicating that most scatterers are Rayleigh. The spread may come from the uncertainty in estimates, which is inversely proportional to $\rho_{\text {hv }}$. Note that the modal $\rho_{\mathrm{hv}}$ is about 0.5 characterizing non-meteorological scatterers. Values this small increase the uncertainly of all polarimetric variables [19]. Positive ZDRS prevail as expected from horizontally oriented small scatterers. However, there are negative values, which, we speculate, are caused by small vertically oriented smoke debris.

The histograms of reflectivity in the case of Little Bear fire is skewed toward larger Zes (peak is at about $20 \mathrm{dBZ}$ ) and maximum values reach $30 \mathrm{dBZ}$. The $Z$ e histogram from the brush fire is skewed toward smaller Zes, with the average of about $0 \mathrm{dBZ}$. Considering that the Little Bear fire was consuming forest and was strongest, it may have lofted larger debris causing increase in reflectivity. Further, the Little Bear fire created significant updraft, which may have triggered 
condensation and ice crystal growth that would increase the reflectivity. Doppler velocities exhibit similar spread and the mean values differ because of geometry.

\section{Discussion}

In the Table 1 we list the average values of the polarimetric variables from the three smoke plumes as well as the reported values in [9] (p 2264) and prairie [17] (pD21204). The backscatter differential phase is $\delta\left(^{\circ}\right)$.

Table 1. Radar variables.

\begin{tabular}{llclccc}
\hline Title & $\mathbf{Z}(\mathbf{d B Z})$ & $\mathbf{Z}_{\text {DR }}(\mathbf{d B})$ & $\rho_{\mathrm{hv}}$ & Spread of $\boldsymbol{\delta}(\mathbf{(})$ & $\boldsymbol{\sigma}_{\mathbf{v}}\left(\mathbf{m ~ s}^{-1}\right)$ & Distance $(\mathbf{k m})$ \\
\hline Prairie & 10 & 2 & 0.45 & wide & 1.5 & 15 \\
Prairie $^{1}$ & $10-15$ & 2.8 & 0.41 & wide & & 60 \\
Brush & 0 & 4.5 & 0.5 & narrow & 1 & 50 \\
Forest & 12.5 & 4.5 & 0.5 & narrow & 1 & 50 \\
Apartment & 9 & 2 & 0.49 & narrow & & 15
\end{tabular}

${ }^{1}[17], 2[9]$.

Although the average values are comparable, the spreads and shapes of the histograms do not match across the board. The polarimetric variables from the two prairie fires in Oklahoma are very similar and unique in the values of the correlation coefficient and backscatter differential phase. The $\rho_{\mathrm{hv}}$ histograms are skewed toward zero and the histograms of $\Phi_{\mathrm{DP}}$ are much wider than the corresponding histograms in the other cases. We remind readers that the backscatter differential phase matters here and is equal to the difference $\Phi_{D P}-\left\langle\Phi_{D P}\right\rangle$, where the brackets signify the average value, which in the case of sparse scatterers (as here) is equal to the system differential phase. The dominant low values of $\rho_{\mathrm{hv}}$ and the wide spread of backscatter differential phase we attribute to continuous quick reorientation (i.e., thumbing, fluttering, spinning) of the smoke debris. This is also the reason that the correlation coefficient from smoke is considerably smaller than the one from insects.

The ZDR histograms in all cases of Table 1 are very similar, [9] (see Fig. 2) and [17] (Fig. 1), in shape and spread. They overlap the values produced by birds and insects. Also similar are the mean values and spreads of the Doppler spectrum widths suggesting that the turbulence and/or wind shear contributions may have been comparable.

The $Z$ histogram from the prairie fire (Fig. 5) is compatible with the one from the forest fire in New Mexico (Fig. 15). Both have a peak close to $20 \mathrm{dBZ}$ and the maximum values of about 28 to dBZ (Fig. 5 and Fig. 15).

The smoke plume produced by the forest fire had a strong updraft, which lofted scatterers to about $8 \mathrm{~km}$ MSL, well above the liquid condensation level. Therefore, we expect that the updraft crated some cloud particles that mixed with the smoke scatterers dominating the returns. The prairie and the brush fires brought the smoke to the top of the planetary boundary layer, but no further. 


\section{Conclusions}

We have documented polarimetric radar observations of smoke plumes caused by wildfires of different origin. One is a grass fire in a prairie of Oklahoma, one is a shrub fire in California, and one is a forest fire in New Mexico. We contrast the histograms of the polarimetric variables from these plumes to the histograms from the scatterers in the planetary boundary layer background. From these observations, one can construct fuzzy logic or Bayesian type classifiers of radar returns from fire plumes. The most discriminating variables are reflectivity $Z$ and correlation coefficient $\rho \mathrm{hv}$. Furthermore, we compare reflectivities measured with a $10 \mathrm{~cm}$ wavelength WSR-88D to the ones measured with a $5 \mathrm{~cm}$ TDWR to infer the dominant sizes of scatterers. As an aside, we also compare background reflectivities of data in Oklahoma and conclude that the principal contributors are insects and birds. While the insects are Rayleigh scatterers at both wavelengths, the birds scatter in the Mie regime at the $5 \mathrm{~cm}$ wavelength. We use Computational Electro Magnetics (CEM) tools to model the plumes and deduce sizes and orientation of the dominant scatterers.

Unlike satellite, radar can observe smoke irrespective of the environmental conditions like day, night, or cloud cover. Therefore, it can serve authorities and the public for several purposes. Radar observations of smoke may provide advance information about the potential degradation of air quality. Knowing location and progression of fire can be useful to airport authorities, especially for small municipal airports. Predicting contamination of water resources by falling smoke debris, and identifying barren regions prone to mudslides is another useful information present in the data from polarimetric weather radars.

Author Contributions: Conceptualization, writing, and part of analysis D. Zrnic; part of analysis and several figures, P. Zhang; interpretation, theory and editing, V. Melnikov; computational electromagnetics and part of analysis Dj. Mirkovic.

Funding: Funding for this study was provided in part by the NOAA/Office of Oceanic and Atmospheric Research under NOAA-University of Oklahoma Cooperative Agreement NA17RJ1227 US Department of Commerce.

\section{Acknowledgments:}

Ms. Kari Greer, USGS, for the photo of the Little Bear fire and information.

Conflict of interest: The authors declared no conflicts of interest.

\section{References}

1. Hoover, K.; Hanson, L.A. Wildfire Statistics. Congressional Research Services (CRS) In Focus, 2019, report. Available at www.crs.gov.

2. National Park Service. Wildland Fire and Evaluations. 2019. https://www.nps.gov/articles/wildfire-causes-and-evaluation.htm

3. Banta, R.M.; Oliver, L.D.; Holloway, E.T.; Kropfli, R.A.; Bartram, B.W.; Cupp, R.E.; Post, M.J. Smoke-column observations from two forest fires using Doppler lidar and Doppler radar. J. Appl. Meteor. 1992, 31, pp. 1328-1349. 
4. Hufford, G.L; Keely, H.L.; Sparkman, G.W. Use of Real-Time Multisatellite and Radar Data to Support Forest Fire Management. Weather Forecast. 1998, 14, pp. 592-605.

5. Saraiva, E.A.; Soares, R.V.; Batista, A.C.; Tertuliano, H.; Gomes, A.M. Monitoring forest fires and burnings with weather radar, Chapter 5 in Advances in Forest Fire Research. 2014, Coimbra University Press: Coimbra, Portugal, pp. 1436-1443.

6. Rogers, R. R.; W. O. Brown. Radar observations of a major industrial fire. Bull. Amer. Meteor. Soc. 1997, 78, pp. 803-814.

7. Erkelens, J. S.; Venema, V. K. C.; Russchenberg, H. W. J. Coherent Particle Scatter in Smoke and Cumulus Clouds. Proceedings of Igarss99. 1999, Hamburg, 28 June - 2 July 1999, pp. 687689. Available at: http://irctr.et.tudelft.nl/reports/1999/cohsmoke.pdf

8. Melnikov, V.M.; Zrnic, D.S.; Rabin, R.M; Zhang, P. Radar polarimetric signatures of fire plumes in Oklahoma. Geoph. Res. Let. 2008, 35.

9. Jones, T.A.; Christopher, S. A.; Petersen, W. Dual-Polarization Radar Characteristics of an Apartment Fire, J. Atmos, Oceanic Technol. 2009, 26, pp. 2257-2269.

10. Doviak, R.J.; Zrnic, D.S. Doppler Radar and Weather Observations. $2^{\text {nd }}$ edition; Reprint, Dover Publications: Mineola, USA, 2006.

11. Richardson, L.M.; Cunningham, J.G.; Zittel, W.D.; Lee, R.L.; Ice, R.L.; Melnikov, V.M.; Hoban, N.P.; Gebauer, J.G. Bragg scatter detection by the WSR-88F. Part I: Algorithm Development. J. Atmos, Oceanic Technol. 2017, 34, pp. 465-478.

12. WIPL-D Electromagnetic Simulation Software. Available on line: URL (accessed on sixteen March 2019) http://www.wipl-d.com

13. Djordje, M. Computational electromagnetics for polarimetric radar scatterers: An approach to polarimetric variable modeling of hydrometeors and biota. LAP Lambert Academic Publishing, 2015, 241pp.

14. Hotta, M.; Hayashi, M.; Lanagan, M.T.; Agrawal, D.K.; Nagata, K. Complex Permittivity of Graphite, Carbon Black and Coal Powders in the Ranges of X-band Frequencies (8.2 to 12.4 $\mathrm{GHz}$ ) and between 1 and $10 \mathrm{GHz}$. ISIJ International, 2011, 11, 1766-1772.

15. Zrnic, D. S.; Ryzhkov, A.V. Observations of insects and birds with a polarimetric radar. IEEE Trans. Geosci. Remote Sens. 1998, GE-36, 661-668.

16. Melnikov, V.M. Simultaneous transmission mode for polarimetric WSR-88D. National Severe Storms Laboratory, Report, June 2004. Norman OK. p. 85. Available at www.nssl.noaa.gov/publications/wsr88d_reports/

17. Melnikov, V.M.; Zrnic D.S.; Rabin, R.M. Polarimetric properties of smoke plumes: a model. J. Geophys. Res. 2009, 114, D21204.

18. Gosard, E.E. Radar research on the atmospheric boundary layer. Radar in Meteorology, D. Atlas, Ed; 1990, American Meteorological Society: Boston, USA.

19. Ryzhkov A. V.; Zrnic, D.S. Radar Polarimetry for Weather Observations. Springer, Cham, Switzerland. 2019, p 486. 